\title{
SKRINING KAKI DIABTES UNTUK DETEKSI DINI LUKA KAKI DIABETES PADA PASIEN DIABETES
}

\section{Diabetic Foot Screening for Early Detection Diabetic Foot Ulcer in Diabetic Patient}

\author{
Juhelnita Bubun ${ }^{1}$, Saldy Yusuf ${ }^{2}$, Yuliana Syam², Wahyu Hidayat ${ }^{3}$, Suharno Usman ${ }^{4}$
}

1. Magister Keperawatan Universitas Hasanuddin

2. Dosen Magister Keperawatan Universitas Hasanuddin

3. STIKES Mega Buwana

4. AKPER Sawerigading ${ }^{4}$

\section{Riwayat artikel}

Diajukan: 16 Agustus 2019

Diterima: 23 September 2020

\section{Penulis Korespondensi:}

- Juhelnita Bubun

- Fakultas Keperawatan, Universitas Hasanuddin

- bubunjuhelnita@gmail.c om

\section{Kata Kunci:}

Skrining Kaki Diabetes, Neuropati, Angiopati

\begin{abstract}
Abstrak
Latar Belakang: Prognosis LKD yang tidak dirawat dengan baik akan berdampak buruk yaitu amputasi bahkan kematian sehingga dibutuhkan tindakan pencegahan yaitu skrining kaki diabetes. Tujuan dari review ini, untuk mengetahui metode skrining kaki diabetes untuk mencegah terjadi luka kaki diabetes (LKD). Metode database yang digunakan pada pencarian artikel yaitu pubmed, wiley dan science direct. Hasil: kata kunci yang digunakan diabetic foot screening OR diabetes foot screening jumlah artikel yang didapatkan 39 artikel dari tiga database dan artikel yang menjadi kriteria inklusi artikel, artikel tahun 2013-2018, merupakan hasil penelitian, sesuai tema scoping review dan artikel full text, sehingga terdapat empat artikel yang terinklusi. Dari artikel tersebut dua artikel yang membahas metode skrining kaki diabetes untuk mendeteksi neuropati dan dua artikel yang membahas metode skrining kaki diabetes untuk mendeteksi angiopati. Skrining kaki diabetes untuk mendeteksi neuropati dapat menggunakan metode sudoscan yang dapat mendeteksi 34\% tidak ada neuropati, tanpa gejala 69\% dan dengan gejala $61,7 \%$. Metode Ipswich touch test (IpTT) dapat digunakan oleh tenaga non professional di rumah dan klinik dalam mendeteksi neuropati dengan sensitivitas $78,3 \%$ dan $81,2 \%$, spesifitas 93,9\% dan 96,4\%. Metode dalam mendeteksi angiopati adalah ankle brachialis index (ABI). Kombinasi hasil palpasi nadi yang lemah /hilang dan ABI yang abnormal menghasilkan sensitivitas dan nilai prediksi negatif tertinggi (92,3\% dan 89,8\%) penyebab peripheral arterial disease (PAD). Kesimpulan: metode skrining kaki diabetes untuk mendeteksi neuropati terdiri atas beberapa metode yang aman untuk digunakan. ABI dapat digunakan mendeteksi PAD.
\end{abstract}

\section{Abstract}

Background: The prognosis of diabetic food ulcer (DFU) that is not treated properly will have a negative impact, namely amputation and even death, so that precautions are needed namely screening for diabetic foot. The purpose of this review, is to find out about diabetic foot screening methods to prevent diabetes foot ulcer. Database methods used in article search are pubmed, wiley and science direct. Results: keywords used diabetic foot screening OR diabetes foot screening the number of articles obtained 39 articles from three databases and articles that are the criteria for article inclusion, articles 2013-2018, are the results of the study, according to the theme of scoping review and full text articles, so there are four articles were included. From the articles, two articles discussed diabetes foot screening methods to detect neuropathy and two others article to detect angiopathy. Diabetes foot screening to detect neuropathy can use sudoscan method which can detect $34 \%$ no neuropathy, no symptoms $69 \%$ and $61.7 \%$ symptoms. The Ipswich touch test (IpTT) method can be used by non-professionals in the home and clinic in detecting neuropathy with a sensitivity of $78.3 \%$ and $81.2 \%$, specificity $93.9 \%$ and $96.4 \%$. The method for detecting angiopathy is ankle brachialis index (ABI). The combination of weak / missing pulse palpation and abnormal ABI results in the highest sensitivity and negative predictive value $(92.3 \%$ and $89.8 \%$ ) causing peripheral arterial disease (PAD). 
Conclusion: diabetes foot screening method for detecting neuropathy consists of several safe methods to use. ABI can be used to detect PAD.

\section{PENDAHULUAN}

Penyakit diabetes mellitus (DM) merupakan penyakit degenerative yang memiliki komplikasi neuropati dan angiopati. Kedua hal ini merupakan penyebab utama terjadi LKD. Adapun prevalensi resiko LKD di Indonesia timur yaitu sebanyak $55.4 \%$ dan prevalensi LKD $12.0 \%$ (Yusuf et al., 2016). Kejadian resiko luka kaki diabetes sebagai komplikasi dari neuropati di tunjang oleh penelitian yang mengemukakan sebanyak 203 pasien DM terdapat 34 orang mengalami neuropati, 23 orang PAD , 24 orang mengalami LKD dan 39 beresiko mengalami LKD (Tindong et al., 2018). Penelitian lain yang sejalan dengan hal tersebut menunjukkan terdapat 76 pasien $(\mathrm{n}=189)$ mengalami LKD yang disebabkan neuropati (Pemayun \& Naibaho, 2017); sebesar $70 \%$ LKD akibat peripheral artery occlusive disease (PAOD), $17 \%$ berada pada grade 3 ( klasifikasi pedis) dan 9\% berada pada grade 3 neuropati (klasifikasi sensasi pedis) (Amadoua et al., 2019). Hal ini menunjukkan bahwa komplikasi yang di timbulkan DM tidak hanya menyebabkan neuropati dan gangguan vascular tetapi juga dapat menyebabkan LKD.

Prognosis LKD yang tidak dirawat dengan baik akan berdampak buruk. Amputasi merupakan salah satu dampak dari LKD yang tidak terawat (Quilici, Del Fiol, Vieira, \& Toledo, 2016; Sadriwala, Gedam, \& Akhtar, 2018). Dampak terburuk dari LKD adalah kematian (Martins-Mendes et al., 2014; Ndosi et al., 2017). Buruknya resiko yang timbul akibat LKD, maka dibutuhkan suatu tindakan pencegahan LKD dan salah satunya yaitu dengan skrining kaki diabetes.

Skrining kaki diabetes merupakan langka awal dalam mengidentifikasi resiko LKD. Pasien DM yang melakukan skrining kaki memiliki resiko lebih rendah mengalami amputasi dibandingkan pasien DM yang tidak melakukan skrining kaki diabetes (Ang, Yap, Hons, \& Saxena, 2017). Penelitian lain menunjukkan bahwa pasien DM yang melakukan skrining kaki diabetes terbebas dari komplikasi kaki diabetes (Ravon \& Ravon, 2017). Namun, perlu diketahui metode skrining yang digunakan dalam mendeteksi LKD, untuk itu tujuan scoping review in imengidentifikasi metode skrining kaki diabetes dalam mendeteksi LKD.

\section{Metode}

Tujuan review ini, mengidentifikasi metode skrining kaki diabetes untuk mendeteksi neuropati dan angiopati, sebagai upaya pencegahan LKD. Pertanyaan dalam review ini "Apakah metode skrining kaki diabetes dapat di gunakan untuk mendeteksi luka kaki diabetes pada pasien diabetes?" Framework penelitian yaitu konsep, skrining kaki diabetes merupakan langka awal dalam mengidentifikasi resiko LKD. Skrining kaki diabetes dilakukan sejak pasien terdiagnosa diabetes tipe 2 dan 5 tahun setelah pasien terdiagnosa DM tipe 1. Pemeriksaan kaki diabetes sebaiknya dilakukan satu kali dalam setahun, namun bila ditemukan resiko terjadi LKD seperti neuropati maka pemeriksaan kaki diabetes dapat di tingkatkan lagi. Adapun fungsi dari skring kaki diabetes adalah untuk mendeteksi neuropati dan angiopati yang merupakan penyebab utama LKD. Konteks, neuropati merupakan kerusakan saraf berupa hilangnya sensasi rasa/mati rasa. Angiopati adalah penyempitan pembuluh darah menyebabkan gangguan aliran darah ke seluruh tubuh. Neuropati dan angiopati merupakan faktor utama penyebab LKD. Kriteria inklusi dan eksklusi dalam review ini adalah artikel yang berfokus pada skrining kaki diabetes dalam mendeteksi neuropati dan angiopati dan artikel kuantitatif. Adapun kriterian ekslusi yaitu artikel review. Strategi pencarian review ini yaitu adalah pubmed, wiley, science direct. Adapun kata kunci yang digunakan dalam data base pubmed, wiley dan science direct adalah (diabetes foot screening) OR (diabetes foot screening). Artikel yang digunakan dalam scoping review ini kami batasi yaitu artikel tahun 2013-2018, artikel penelitian, artikel yang di gunakan sesuai dengan tema scoping review ini, selanjutnya artikel full text dan artikel yang berbahasa inggris. Adapun artikel yang terinklusi sebanyak 4 artikel, yaitu 2 artikel cross sectional dan 2 prospektif.

\section{HASIL}

Metode skrining kaki diabetes untuk mendeteksi neuropatimerupakan pemeriksaan untuk mengetahuifungsi saraf pada pasien diabetes. Dalam scoping review ini terdapat 2 artikel yang meneliti mengenai metode skrining untuk mendeteksi neuropati (Mao et al., 2017; Sharma, Kerry, Atkins, \& Rayman, 2014). Metode skrining untuk mendeteksi angiopati merupakan pemerikasaanuntuk mengetahui aliran darah pada pasien diabetes. Dalam scoping review ini juga terdapat 2 artikel yang meneliti metode 
skrining kaki diabetes untuk mendeteksi angiopati (Aubert et al., 2013; Xu et al., 2019). Penelitian mengenai IpTT dapat mendeteksi neuropati bertujuan menentukan apakah IpTT dapat dilakukan oleh tenaga non professional dirumah dan di klinik dalam mendeteksi neuropati. Hasil penelitian menunjukkan bahwa IpTT dapat dilakukan oleh tenaga nonprofessional dengan sensitivitas di rumah dan di klinik $78.3 \%$ dan $81.2 \%$ dan spesifitas $93.9 \%$ dan $94.4 \%$ (Sharma et al., 2014). Penelitian metode sudoscan bertujuan mengevaluasi distal diabetes asimtomatik polyneuropati simetris menggunakan sudoscan dengan jumlah pasien diabetes 394 orang. Hasil penelitian menunjukkan. Hasil penelitian menunjukkan bahwa metode sudoscan dapat mendeteksi sebanyak 69\% tanpa gejala dan $61,9 \%$ tanpa gejala neuropati pada pasien diabetes (Mao et al., 2017). Metode skrining kaki diabetes untuk mendeteksi angiopati dalam scoping review ini adalah menggunakan metode ABI (Aubert et al., 2013; Xu et al., 2019). Penelitian metode ABI dan palpasi yang pertama bertujuan mengetahui dampak kalsifikasi vaskuler perifer pada alat $\mathrm{ABI}$ dan palpasi nadi dengan jumlah pasien 400 orang. Hasil penelitian menyebutkan bahwa kombinasi hasil palpasi nadi yang lemah /hilang dan ABI yang abnormal menghasilkan sensitivitas dan nilai prediksi negative tertinggi $(92,3 \%$ dan 89,8\%) penyebab PAD (Aubert et al., 2013). Penelitian selanjutnya yang juga meneliti mengenai ABI dengan jumlah pasien 634 orang diabetes tipe 2 . Hasil penelitian menyatakan bahwa kejadian coronary arteri desease sebanyak 90\% pasien memiliki ABI rendah dan 30\% memilki ABI normal, 25\% memilki ABI tinggi (Xu et al., 2019).

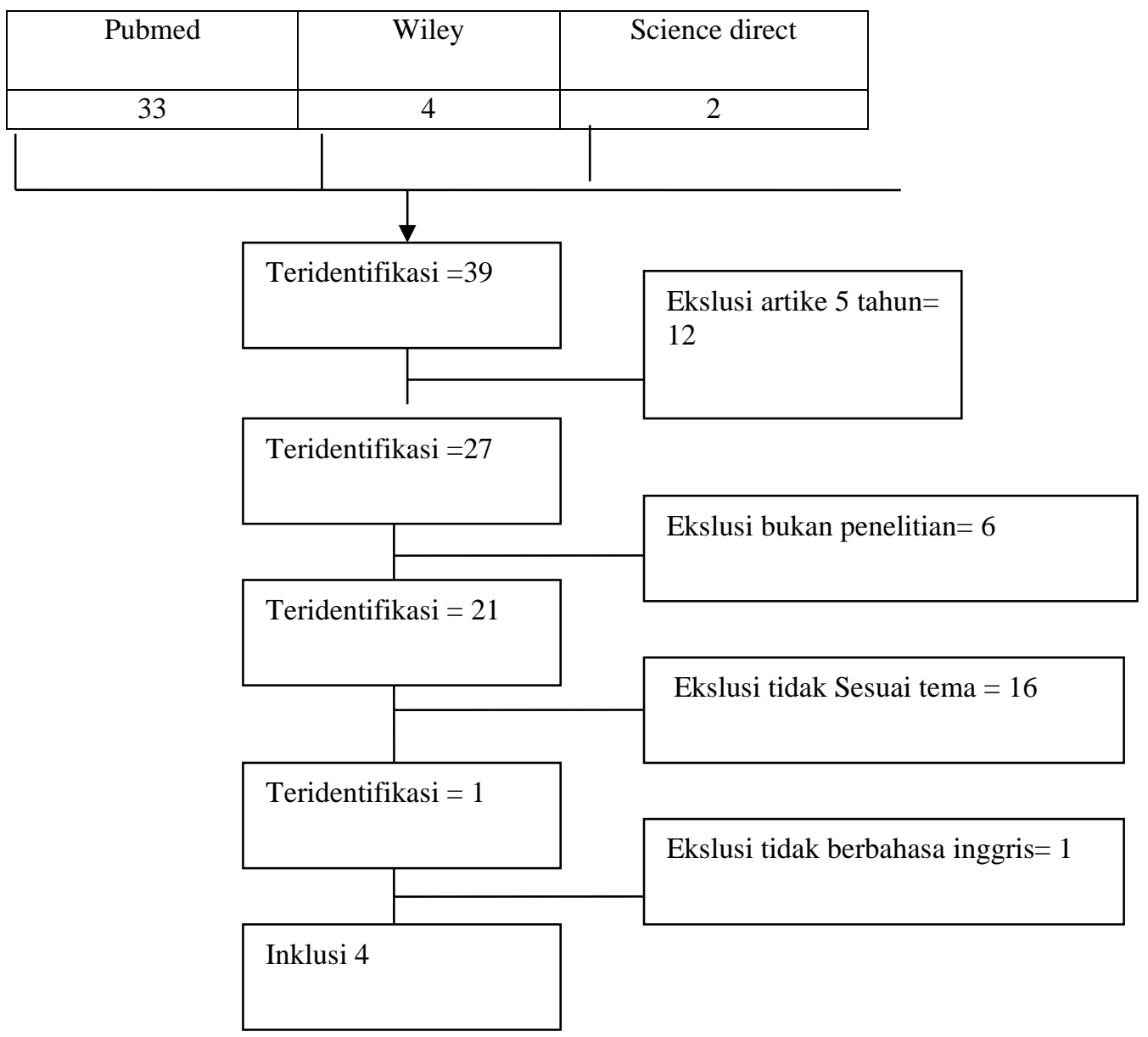

Gambar: algoritma pencarian 


\begin{tabular}{|c|c|c|c|c|c|c|}
\hline No & $\begin{array}{l}\text { Author / } \\
\text { tahun }\end{array}$ & Nama Jurnal & Judul & Tujuan & Metode & Hasil \\
\hline 1 & $\begin{array}{l}\text { Sharma } \\
\text { S/2014 }\end{array}$ & $\begin{array}{l}\text { Diabetes } \\
\text { medicine }\end{array}$ & $\begin{array}{l}\text { Care Delivery The Ipswich } \\
\text { Touch Test: a simple and } \\
\text { novel method to screen } \\
\text { patients with diabetes at } \\
\text { home for increased risk of } \\
\text { foot ulceration }\end{array}$ & $\begin{array}{l}\text { Menentukan Iptt dapat dilakukan } \\
\text { tenaga non professional dan } \\
\text { menentukan nilai signifikasi }\end{array}$ & prospective & $\begin{array}{c}\text { IpTT di rumah memiliki sensitivitas } 78.3 \% \\
\text { dan spesifitas } 93.9 \% \text {. nilai prediktif } \\
\text { pemeriksaan kaki beresiko positive } 81.2 \% \\
\text { dan negative } 92.8 \%\end{array}$ \\
\hline 2 & $\begin{array}{l}\text { C. E. } \\
\text { Aubert/ } \\
2013\end{array}$ & $\begin{array}{l}\text { Diabetes } \\
\text { medicine }\end{array}$ & $\begin{array}{c}\text { Complications } \\
\text { Influence of peripheral } \\
\text { vascular calcification on } \\
\text { efficiency } \\
\text { of skrining tests for } \\
\text { peripheral arterial occlusive } \\
\text { disease } \\
\text { in diabetes }\end{array}$ & $\begin{array}{c}\text { Mengetahui dampak kalsifikasi } \\
\text { vaskuler perifer pada alat ABI dan } \\
\text { palpasi nadi }\end{array}$ & $\begin{array}{c}\text { Cross } \\
\text { sectional }\end{array}$ & $\begin{array}{l}\text { kombinasi hasil palpasi nadi yang lemah } \\
\text { /hilang dan ABI yang abnormal } \\
\text { menghasilkan sensitivitas dan nilai prediksi } \\
\text { negative tertinggi (92,3\% dan } 89,8 \%) \\
\text { penyebab PAD }\end{array}$ \\
\hline 3 & $\begin{array}{l}\text { Lei xu/ } \\
2018\end{array}$ & $\begin{array}{c}\text { Diabetes } \\
\text { metab }\end{array}$ & $\begin{array}{c}\text { The value of ankle- } \\
\text { branchial index skrining for } \\
\text { cardiovascular } \\
\text { disease in type } 2 \text { diabetes }\end{array}$ & $\begin{array}{c}\text { Mengetahui hubungan } \\
\text { pemeriksaan ABI dengan } \\
\text { penyakit kardiovaskuler pada } \\
\text { pasien tipe 2 }\end{array}$ & $\begin{array}{c}\text { Cross } \\
\text { sectional }\end{array}$ & $\begin{array}{l}\text { Prevalensi CAD pada kelompok ABI rendah } \\
(90 \%) \text { secara signifikan lebih tinggi } \\
\text { dibandingkan dengan kelompok ABI normal } \\
(33 \%) \text { dan kelompok ABI tinggi }(25 \%) \\
\text { (keduanya } \mathrm{P}<0,01)\end{array}$ \\
\hline 4 & $\begin{array}{c}\text { Feo mao/ } \\
2017\end{array}$ & $\begin{array}{c}\text { Journal } \\
\text { diabetes } \\
\text { investigation }\end{array}$ & $\begin{array}{l}\text { Sudoscan is an effective } \\
\text { skrining method for } \\
\text { asymptomatic diabetes } \\
\text { neuropathy in Chinese } \\
\text { type } 2 \text { diabetes mellitus } \\
\text { patients }\end{array}$ & $\begin{array}{l}\text { Untuk mengetahui fungsi tes } \\
\text { sudomotor, Sudoscan, sebagai } \\
\text { metode skrining untuk evaluasi } \\
\text { distal diabetes asimptomatik } \\
\text { polyneuropathy simetris pada } \\
\text { pasien diabetes tipe } 2 \text { Cina }\end{array}$ & $\begin{array}{c}\text { Cross } \\
\text { sectional }\end{array}$ & $\begin{array}{c}\text {.sudoscan secara signifikan dapat digunakan } \\
\text { dalam mendeteksi neuropati (sensitivitas } \\
78 \% \text { dan spesifisitas } 98 \%) .\end{array}$ \\
\hline
\end{tabular}




\section{PEMBAHASAN}

Ipswich touch test merupakan tes sederhana yang dapat digunakan oleh tenaga non professional dalam mendeteksi neuropati. Hal ini didukung penelitian yang menunjukkan bahwa metode IpTT dalam mendeteksi resiko luka kaki diabetes memiliki sensitivitas, spesivisitas, AUIC, PPV, NPV, +LHR dan, -LHR saat dibandingkan dengan nilai $\mathrm{VPT} \leq 25 \mathrm{~V}, \mathrm{NDS} \leq 6,10$-g MF tes memiliki nilai signifikan, masing-masing $\mathrm{k}=0.48$ $(p<0.0001), c \alpha 0,6, k=0.566, \quad(p=0,0001), \quad c \alpha$ $0.726, \quad \mathrm{k}=0.653, \quad \mathrm{p}=(\mathrm{p}<0.0001), \quad \mathrm{c} \alpha \quad 0.798$ (Madanat, Sheshah, Badawy, Abbas, \& AlBakheet, 2015). Hal tersebut juga ditunjang sebuah penelitian yang melaporkan bahwa IpTT dapat mengkonfirmasi gejala neuropati pada pasien diabetes dengan sensitivitas 72,7\%-100\% dan bebas neuropati sekitar (50\%-100\%) (Yuliani, Sulaeha, Sarina, \& Yusuf, 2017). IpTT merupakan tes sederhana yang dapat digunakan oleh non professional dan professional.

Sudoscan merupakan tes yang mengevaluasi fungsi kelenjar keringat dalam mendeteksi neuropati serat kecil distal. Sudoscan dapat digunakan untuk mendeteksi neuropati. Hal ini di dukung penelitian yang menunjukkan bahwa sudoscan secara signifikan dapat digunakan dalam mendeteksi neuropati (sensitivitas 78\% dan spesifisitas 98\%) (Casellini, Parson, Richardson, Nevoret, \& Vinik, 2013). Penelitian lain yang juga menunjukkan bahwa sudoscan dapat mendeteksi neuropati dengan benar $73 \%$ pasien mengalami neuropati dan $62 \%$ tanpa neuropati serta mudah untuk digunakan (Yajnik, Kantikar, Pande, \& Deslypere, 2012). Penggunaan sudoscan signifikan dalam mendeteksi neuropati pada serat kecil distal pada penderita diabetes kurang dan di atas 5 tahun masing-masing $(p=0.0007$ dan $p=0.0058)$, sangat sederhana, tidak membutuhkan persiapan dan nyaman bagi pasien (Ramirez, Dominguez, Ayala, Uribe, \& Negrete, 2019). Metode sudoscan merupakan salah satu metode mendeteksi neuropati yang efektif dan mudah digunakan dalam mendeteksi neuropati. Angiopati merupakan penyempitan pembuluh darah yang menyebabkan penyakit pembuluh darah arteri perifer (PAD), yang dapat menyebabkan gangguan pada jantung dan seluruh tubuh. Skrining kaki diabetes untuk mendeteksi angiopati dilakukan dengan menggunakan metode ankle brachialis index (ABI) dan palpasi nadi dorsalis pedis dan posterior tibialis. Adanya kombinasi antara lemahnya/ hilang nadi dengan ABI yang abnormal menyebabkan PAD. Hal ini di dukung sebuah penelitian yang menunjukkan gejala PAD ada pada 6,5\% pasien dari 533 pasien tidak teraba nadi pada pergelangan kaki dan sebesar $20,0 \%$ pasien memilki ABI yang abnormal $(>0,90)$ (Bozkurt, Tasci, Tabak, Gumus, \& Kaplan, 2011). Penelitian lain yang menunjang hal tersebut menunjukkan bahwa sebanyak 123 $(65,7 \%)$ kasus PAD dapat terdiagnosa menggunakan ABI (Aerden et al., 2011). Metode ABI dapat digunakan pada penderita diabetes yang diduga mengalami PAD dengan ciri-ciri mengeluh nyeri daerah kaki saat beraktivitas dan proses penyembuhan luka menunjukkan tidak ada kemajuan, riwayat merokok.

\section{KESIMPULAN}

Metode yang digunakan untuk skrining kaki terdiri atas beberapa metode yang aman dan mudah untuk digunakan seperti ABI untuk mendeteksi PAD. Pemeriksaan kaki diabetes dapat dilakukan pada pasien yang di duga mengalami komplikasi kaki diabetes (neuropati \& angiopati).

\section{DAFTAR PUSTAKA}

Aerden, D., Massaad, D., Kemp, K. Von, Tussenbroek, F. Van, Debing, E., Keymeulen, B., \& Brande, P. Van Den. (2011). The Ankle e Brachial Index and the Diabetic Foot: A Troublesome Marriage. Annals of Vascular Surgery, 25(6), 770-777. https://doi.org/10.1016/j.avsg.2010.12.0 25

Amadoua, C., Carlier, A., Amouyald, C., Bourron, O., Aubert, C., Couture, T., ... Hartemannmadou, A. (2019). Five-Year Mortality in Patients with Diabetic Foot Ulcer During 2009 - 2010 was Lower Than Expected. Diabetes \& Metabolism, (1113), 1-6. https://doi.org/https://doi.org/10.1016/j. diabet.2019.04.010

Ang, G. Y., Yap, C. W., Hons, P., \& Saxena, N. (2017). Effectiveness of Diabetes Foot Screening in Primary Care in Preventing Lower Extremity Amputations, 46(11), 417-423.

Aubert, C. E., Cluzel, P., Kemel, S., Michel, P., Dadon, M., Hartemann, A., \& 
Bourron, O. (2013). Research :

Complications Influence of peripheral vascular calcification on efficiency of screening tests for peripheral arterial occlusive disease in diabetes - a crosssectional study, 5-7.

https://doi.org/10.1111/dme.12309

Bozkurt, A. K., Tasci, I., Tabak, O., Gumus, M., \& Kaplan, Y. (2011). Peripheral artery disease assessed by anklebrachial index in patients with established cardiovascular disease or at least one risk factor for atherothrombosis - CAREFUL Study : A national, multi-center, crosssectional observational study. $B M C$ Cardiovascular Disorders, 11(1), 4. https://doi.org/10.1186/1471-2261-11-4 Casellini, C. M., Parson, H. K., Richardson, M. S., Nevoret, M. L., \& Vinik, A. I. (2013). Sudoscan , a Noninvasive Tool for Detecting Diabetic Small Fiber Neuropathy and Autonomic Dysfunction. Diabetes Technology Dan Therapeutics, 15(11), 948-953. https://doi.org/10.1089/dia.2013.0129

Madanat, A., Sheshah, E., Badawy, E. B., Abbas, A., \& Al-Bakheet, A. (2015). Utilizing the Ipswich Touch Test to simplify screening methods for identifying the risk of foot ulceration among diabetics: The Saudi experience. Primary Care Diabetes, 9(4), 304-306. https://doi.org/10.1016/j.pcd.2014.10.00 7

Mao, F., Liu, S., Qiao, X., Zheng, H., Xiong, Q., Wen, J., ... Lu, B. (2017). Sudoscan is an effective screening method for asymptomatic diabetic neuropathy in Chinese type 2 diabetes mellitus patients, 8(3), 363-368. https://doi.org/10.1111/jdi.12575

Martins-Mendes, D., Monteiro-Soares, M., Boyko, E. J., Ribeiro, M., Barata, P., Lima, J., \& Soares, R. (2014). The independent contribution of diabetic foot ulcer on lower extremity amputation and mortality risk. Journal of Diabetes and Its Complications, 28(5), 632-638. https://doi.org/10.1016/j.jdiacomp.2014. 04.011

Ndosi, M., Brown, A. W.-H. S., Michael, Backhouse, Lipsky, B. A., Bhogal, M., ... Nelson, E. A. (2017). Research : Complications Prognosis of the infected diabetic foot ulcer : a 12-month prospective observational study. Diabetic Medicine, 35(1), 78-88. https://doi.org/10.1111/dme.13537

Pemayun, T. G. D., \& Naibaho, R. M. (2017). Clinical Profile and Outcome of Diabetic Foot Ulcer, a View From Tertiary Care Hospital in Semarang, Indonesia. Diabetic Foot \& Ankle, 8(1), $1-8$.

https://doi.org/10.1080/2000625X.2017. 1312974

Quilici, M. T. V., Del Fiol, F. de S., Vieira, A. E. F., \& Toledo, M. I. (2016). Risk Factors for Foot Amputation in Patients Hospitalized for Diabetic Foot Infection. Journal of Diabetes Research, 2016, 1-8. https://doi.org/10.1155/2016/8931508

Ramirez, A. C., Dominguez, H., Ayala, M. A. M., Uribe, M. M. R., \& Negrete, A. C. (2019). Early identification of peripheral neuropathy based on sudomotor dysfunction in Mexican patients with type 2 diabetes. $B M C$ Neurology, 19(109), 1-6. https://doi.org/https://doi.org/10.1186/s 12883-019-1332-4

Ravon, V. U., \& Ravon, J. (2017). AN EXPLORATION OF DIABETIC FOOT SCREENING PROCEDURES DATA BY A MULTIPLE CORRESPONDENCE ANALYSIS. De Gruyter, 56(1), 65-73.

Sadriwala, Q. S., Gedam, B. S., \& Akhtar, M. A. (2018). Risk factors of amputation in diabetic foot infections, 5(4), 1399-1402.

Sharma, S., Kerry, C., Atkins, H., \& Rayman, G. (2014). Short Report : Care Delivery The Ipswich Touch Test : a simple and novel method to screen patients with diabetes at home for increased risk of foot ulceration, 1100- 
1103.

https://doi.org/10.1111/dme.12450

Tindong, M., Palle, J. N., Nebongo, D.,

Aminde, L. N., Mboue-djieka, Y.,

Mbarga, N. T. F., ... Choukem, S.

(2018). Prevalence, Clinical

Presentation, and Factors Associated

With Diabetic Foot Ulcer in Two

Regional Hospitals in Cameroon. https://doi.org/10.1177/1534734618764 252

Xu, L., He, R., Hua, X., Zhao, J., Zhao, J., Zeng, H., ... Jia, W. (2019). The value of ankle - branchial index screening for cardiovascular disease in type 2 diabetes, (September 2018), 1-7. https://doi.org/10.1002/dmrr.3076

Yajnik, C. S., Kantikar, V. V, Pande, A. J., \& Deslypere, J. P. (2012). Quick and
Simple Evaluation of Sudomotor Function for Screening of Diabetic Neuropathy, 2012(Dc), 12-15. https://doi.org/10.5402/2012/103714

Yuliani, K., Sulaeha, S., Sarina, S., \& Yusuf, S. (2017). Check Up Diabetic Foot, Deteksi Dini Risiko Luka Kaki Diabetes Pada Pasien Diabetes Mellitus di Makassar : Uji Sensitifitas dan Spesifisitas. Hasanuddin Student Journal, 1(1), 62-65.

Yusuf, S., Okuwa, M., Irwan, M., Rassa, S., Laitung, B., Thalib, A., ... Sugama, J. (2016). Prevalence and Risk Factor of Diabetic Foot Ulcers in a Regional Hospital, Eastern Indonesia. Open Journal of Nursing, 6(1), 1-10. https://doi.org/10.4236/ojn.2016.61001 
Jurnal Ilmiah Keperawatan (Scientific Journal of Nursing), Vol 6, No 2, Tahun 2020 